\title{
Fabrication of Aluminium Nanowires by Differential Pressure Injection
}

\author{
A. Hashoosh, ${ }^{1}$ H. Hirshy, ${ }^{2}$ E. B. Brousseau, ${ }^{2}$ and A. Moosa ${ }^{3}$ \\ ${ }^{1}$ Department of Materials Engineering, The University of Technology, Baghdad, Iraq \\ ${ }^{2}$ Cardiff School of Engineering, Cardiff University, Cardiff CF24 3AA, UK \\ ${ }^{3}$ Department of Materials Engineering, Technical College-Baghdad, Baghdad, Iraq
}

Correspondence should be addressed to A. Moosa; ahmeda1752@yahoo.com

Received 25 June 2013; Accepted 24 July 2013

Academic Editors: S. K. Dhara and M. R. Ferreira

Copyright (C) 2013 A. Hashoosh et al. This is an open access article distributed under the Creative Commons Attribution License, which permits unrestricted use, distribution, and reproduction in any medium, provided the original work is properly cited.

\begin{abstract}
The reported study aims to demonstrate the application of a simple technique, which is referred to as pressure differential injection, to prepare metallic nanowires. This technique relies on the difference in pressure between the inside of sealed nanochannels of an anodic aluminium oxide (AAO) substrate and the ambient atmosphere to inject a molten metal, which is previously deposited on the substrate, into the AAO pores. The application of this technique enabled the fabrication of nanowires in aluminium with diameters comprised between $55 \mathrm{~nm}$ and $65 \mathrm{~nm}$.
\end{abstract}

\section{Introduction}

Among the different structures, which have contributed to the advent of the field of nanotechnology, metallic nanowires have played an important role as these one-dimensional components typically exhibit very different physical properties in comparison to their bulk counterparts due to quantum confinement effects. Such characteristics are of specific interest to meet the demand for the development of future miniaturised systems such as electronic and optical devices. In particular, nanowires in aluminium represent a potential candidate technology for the development of high-density and highresolution microelectronic systems and future energy storage devices [1]. Aluminium has the benefits of low melting point, chemical stability, ductility, good electrical conductivity, and reasonable cost.

However, in order to enable further studies of the properties of such nanostructures as well as their scaledup deployment in potential applications, it is important to ensure that their production can be carried out efficiently, reliably, and cost effectively. A number of techniques have been investigated for the synthesis of nanowires such as electrodeposition [2] and chemical vapour deposition [3]. While these fabrication processes enable the manufacture of nanowires in different materials, they have been reported to show a lack of reliability over the control of the uniformity and the length of the produced nanowires [4]. To overcome these issues, the pressure injection method has been utilised successfully to form nanowires in various metals such as bismuth (Bi) [4], tin ( $\mathrm{Sn}$ ) [5], and $\mathrm{Al}$ [6]. This method relies on injecting a molten metal into the pores of an anodic aluminium oxide (AAO) substrate. In order to fill the AAO channels, external pressure is required for overcoming the surface tension of the molten metal. The necessary pressure can be described by the well-known Washburn equation, which is expressed as follows:

$$
P=-\frac{4 \gamma \cos \theta}{D},
$$

where $D$ is the pore diameter of the AAO substrate used, $\gamma$ is the surface tension of the metallic melt, and $\theta$ is the contact angle between the template and the molten metal. For a given melt, the applied pressure needed is relatively high, and it increases as the size of the pores decreases. For example, in the case of Sn nanowires, 350 bar and 1400 bar are, respectively, required for pore diameter of $60 \mathrm{~nm}$ and $15 \mathrm{~nm}$ [5]. In this study, the surface tension of $\mathrm{Al}$ is taken as 


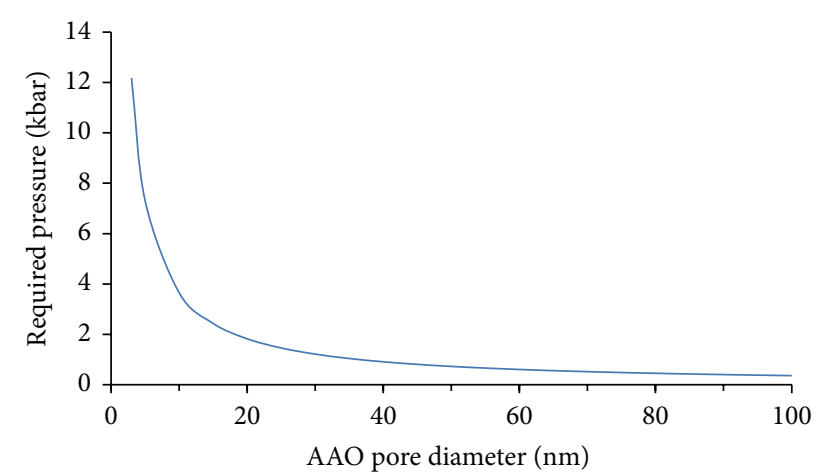

FIgURE 1: Estimated evolution of the required pressure to fill AAO channels with $\mathrm{Al}$ melt as a function of the pore diameter for a contact angle $\theta=180^{\circ}$.

$\gamma=0.914 \mathrm{~N} / \mathrm{m}$ [7] and the contact angle, $\theta$, is considered to be equal to $180^{\circ}$, which represents a conservative value and will give the upper limit for the pressure required. In this way, the evolution of the necessary pressure to be applied to inject molten aluminium could be estimated as a function of the diameter of the AAO pores as shown in Figure 1.

To reach such a high pressure range during the nanowire injection process, two main methods have been utilized, namely, gas injection and vacuum hydraulic pressure injection. The gas-assisted injection technique has been used to manufacture bismuth-antimony (Bi-Sb) alloy nanowires $45 \mathrm{~nm}$ in diameter [8], tellurium- (Te-) doped Bi nanowires $40 \mathrm{~nm}$ in diameter [9], and Bi nanowires as small as $13 \mathrm{~nm}$ in diameter [10]. The vacuum hydraulic pressure injection technique has been proposed as a simple alternative to the gas-assisted method in order to achieve a higher range of applied pressure values. Sn nanowires with diameter as small as $15 \mathrm{~nm}$ [5] as well as Bi nanowires [4] were fabricated with this method. In addition, researchers also investigated the implementation of centrifugal forces applied in vacuum for injecting a lead- ( $\mathrm{Pb}-)$ Bi melt into the channels of an $\mathrm{AAO}$ substrate, which led to the production of $\mathrm{Pb}-\mathrm{Bi}$ nanowires with a diameter of $80 \mathrm{~nm}$ [11]. Sung and coworkers described another alternative injection technique to fill the pores of an AAO substrate, which does not require gas or hydraulic pressure [12]. In particular, the technique consists of using thermal evaporation under vacuum first in order to deposit a thin metallic layer, a few hundreds nm thick, onto the AAO substrate, and then this is followed by heating the film and AAO template above the melting point of the deposited metal under atmospheric pressure. Thus, the injection of the melt into the pores relies on the pressure differential between the outside ambient pressure and the inside of the AAO channels, which are sealed by the metallic film as a result of the thermal evaporation process. Although the technique described by Sung and coworkers led to the fabrication of aluminium nanotubes, the authors believe that by adjusting the process parameters, it could also be used as a simple and cost-effective alternative to existing pressure injection methods for synthesising $\mathrm{Al}$ nanowires. Based on the data shown in Figure 1, a pressure differential below $10 \mathrm{kbar}$ is required to fill melted $\mathrm{Al}$ into $\mathrm{AAO}$ pores with dimensions of $5 \mathrm{~nm}$ and above. Thus, if the value of the atmospheric pressure is taken as 1 bar, then the vacuum required during the initial evaporation process is of $0.1 \mathrm{mbar}$, which is easily achieved by vacuum systems.

In this context, the objective of this study is to demonstrate that the pressure differential method can also be employed to prepare $\mathrm{Al}$ nanowires by suitably controlling the process parameters, namely, the metallic film thickness and the heating time during the injection phase of the process. The remaining part of the paper is organised as follows. The next section presents the experimental procedure used to prepare AAO substrates with varying pores dimensions. This section also describes the experimental technique followed to deposit $\mathrm{Al}$ on the AAO templates as well as the method employed to inject $\mathrm{Al}$ into the AAO pores. Then, the results obtained are presented, and finally the conclusions reached and perspectives for future work are given.

\section{Experimental Procedure}

2.1. Fabrication of the AAO Templates. The AAO substrates were fabricated using the two-step anodization process. In particular, $\mathrm{Al}$ foils with dimensions $30 \mathrm{~mm} \times 20 \mathrm{~mm} \times$ $0.15 \mathrm{~mm}$ and $99 \%$ purity were annealed in an electric furnace. Prior to and following the annealing, the foils were cleaned in an ultrasonic bath with acetone for 5 minutes. Next, the Al samples were treated with a sodium hydroxide $(\mathrm{NaOH})$ solution for 2 minutes in order to remove the oxide layer produced during the annealing step. The samples were then washed with deionized (DI) water before being chemically polished in a solution comprised of $3.5 \mathrm{~mL}$ phosphoric acid $\left(\mathrm{H}_{3} \mathrm{PO}_{4}\right)$ and $4.5 \mathrm{~g}$ of chromium trioxide $\left(\mathrm{CrO}_{3}\right)$ dissolved in $96.5 \mathrm{~mL}$ of water. This polishing step was conducted at $80^{\circ} \mathrm{C}$ for 10 minutes. The cleaned and polished $\mathrm{Al}$ samples were then anodized at $40 \mathrm{~V}$ in $0.3 \mathrm{M}$ oxalic acid for 1 hour using a stainless steel sheet as the cathode. Three samples were produced in this way at the respective temperature of $17^{\circ} \mathrm{C}, 19^{\circ} \mathrm{C}$, and $25^{\circ} \mathrm{C}$ in order to study the influence of the temperature applied during the first anodizing step on the resulting pore diameters. In order to keep the temperature constant during this step, the anodizing cell was cooled in a bath of liquid monoethylene for which the temperature was controlled with a chiller and monitored with a K-type thermocouple. Following this, the aluminium oxide porous film formed was stripped off using a solution of $\mathrm{H}_{3} \mathrm{PO}_{4}$ $(8.75 \mathrm{~mL}), \mathrm{CrO}_{3}(5 \mathrm{~g})$, and water $(241.25 \mathrm{~mL})$ at $50^{\circ} \mathrm{C}$ for 10 minutes. The samples were then washed in DI water and dried. The purpose of this first anodization step is to generate periodic concave hexagonal structures on the Al substrate which can act as the seed pattern for the second anodization. This second step was conducted under the same conditions as the first anodization with the exception that it lasted for 11 hours. Following this, the samples were washed in DI water, and a pore widening treatment was conducted by immersing the samples in a solution of $\mathrm{H}_{3} \mathrm{PO}_{4}(5 \mathrm{~mL})$ and water $(95 \mathrm{~mL})$ at $50^{\circ} \mathrm{C}$ for 10 minutes. 
TABLE 1: e-beam evaporation parameters used.

\begin{tabular}{lc}
\hline Parameter & Value \\
\hline Aluminium purity & $99.999 \%$ \\
Evaporation pressure (mbar) & $4 \cdot 10^{-6}$ \\
e-beam current (mA) & 40 \\
Deposition time (min) & 17 \\
\hline
\end{tabular}

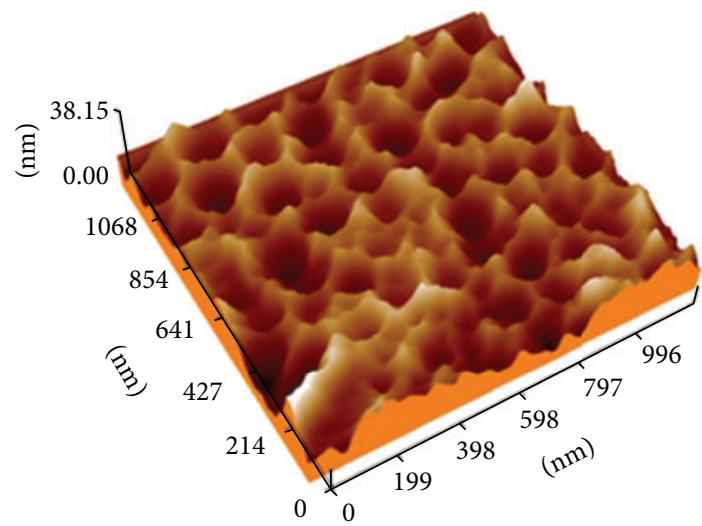

FIgURE 2: AFM scan of the AAO sample processed at $19^{\circ} \mathrm{C}$.

2.2. Fabrication of Al Nanowires by Differential Pressure Injection. An electron beam (e-beam) evaporation system from Edwards (type Auto 500) was used to deposit the aluminium film on top of the surface of the AAO samples. Table 1 summarises the parameters used during this evaporation process. In particular, the evaporation pressure utilised was $4 \cdot 10^{-6} \mathrm{mbar}$, which is well above the pressure required for the injection of the $\mathrm{Al}$ melt as calculated in the previous section. Following this deposition step, the AAO substrates were placed in an electric furnace at $700^{\circ} \mathrm{C}$, which was just above the melting point of $\mathrm{Al}\left(660^{\circ} \mathrm{C}\right)$, for $50 \mathrm{~s}$ under atmospheric pressure.

The final step consisted in dissolving the AAO substrates in order to reveal the nanowires. For this, a solution of sodium hydroxide with a concentration of $5 \mathrm{~g} \mathrm{NaOH}^{+}$and $100 \mathrm{~mL}$ of water was used for 10 minutes. The samples were then washed in deionized water.

2.3. Characterisation Techniques. An atomic force microscope (AFM) from Angstrom Advanced (type CSPMAA3000) was used in noncontact mode to inspect qualitatively the surface of the AAO samples prepared. Figure 2 shows an example of an AFM scan obtained for the sample anodized at a temperature of $19^{\circ} \mathrm{C}$. In addition, a dual focused ion beam (FIB) and scanning electron microscope (SEM) system from Carl Zeiss (type XB1540) were utilised for the complementary quantitative analysis of the AAO samples. In particular, the SEM micrographs obtained were used to measure the pores diameters and the interpore distance, while the FIB was employed to mill the surface of the AAO specimen and thus to reveal their cross-sections. The thickness of the $\mathrm{Al}$ film deposited prior to the injection step was measured using a Dektak surface profiler. Finally, X-ray diffraction (XRD)

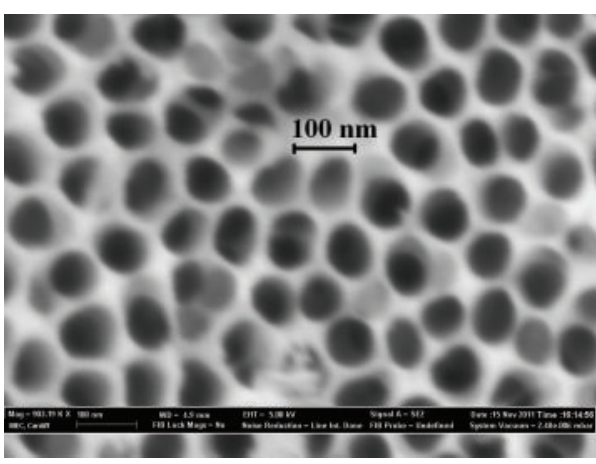

FIGURE 3: SEM micrograph of the AAO surface for the specimen produced at $17^{\circ} \mathrm{C}$.

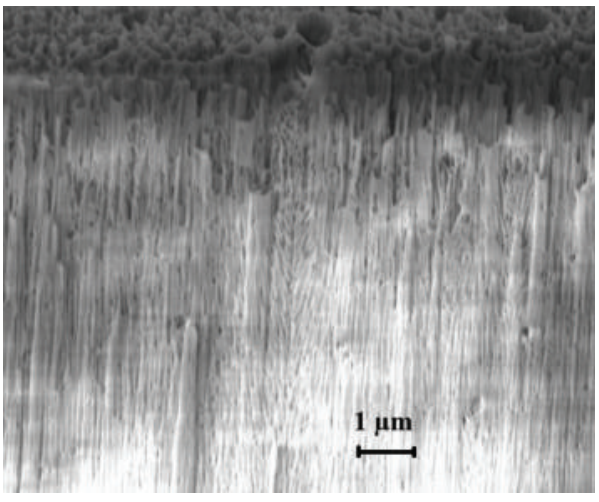

FIGURE 4: SEM micrograph of the cross-section for the AAO specimen produced at $17^{\circ} \mathrm{C}$.

TABle 2: Dimensional characteristics of the AAO specimen obtained.

\begin{tabular}{lcccc}
\hline & $\begin{array}{c}\text { Anodizing } \\
\text { temperature } \\
\left({ }^{\circ} \mathrm{C}\right)\end{array}$ & $\begin{array}{c}\text { Average pore } \\
\text { diameter } \\
(\mathrm{nm})\end{array}$ & $\begin{array}{c}\text { Average } \\
\text { interpore } \\
\text { distance }(\mathrm{nm})\end{array}$ & $\begin{array}{c}\text { Pore } \\
\text { density } \\
\left(\text { pore } / \mathrm{cm}^{2}\right)\end{array}$ \\
\hline Sample 1 & 17 & 75 & 99 & $7.1 \cdot 10^{9}$ \\
Sample 2 & 19 & 83 & 105 & $6.3 \cdot 10^{9}$ \\
Sample 3 & 25 & 103 & 111 & $5.5 \cdot 10^{9}$ \\
\hline
\end{tabular}

analysis (Shimadzu XRD 6000) and SEM micrographs were obtained to characterise the produced nanowires.

\section{Results and Discussion}

Figure 3 shows an example of an SEM micrograph obtained when inspecting the AAO specimen prepared at $17^{\circ} \mathrm{C}$. Such SEM micrographs were recorded for all the samples and in this way, the dimensional characteristics of the AAO substrates could be measured as a function of the anodizing temperature as shown in Table 2.

As it can be seen from this table, the pore diameter increased with the augmentation of the anodizing temperature. This result is consistent with observations made in other studies [13]. This is due to the fact that as the temperature of the electrolyte (i.e., the oxalic acid) is raised, the electrolyte 


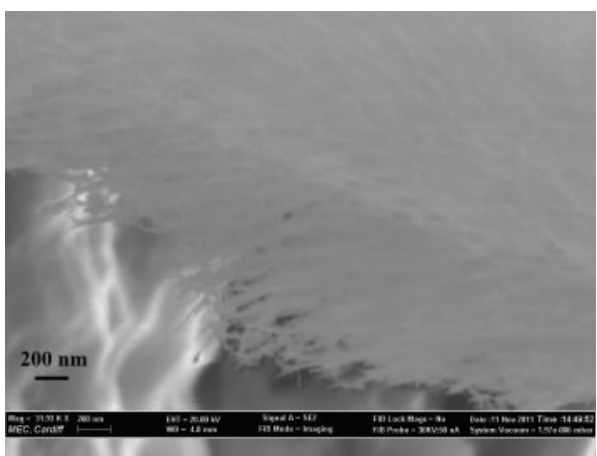

(a)

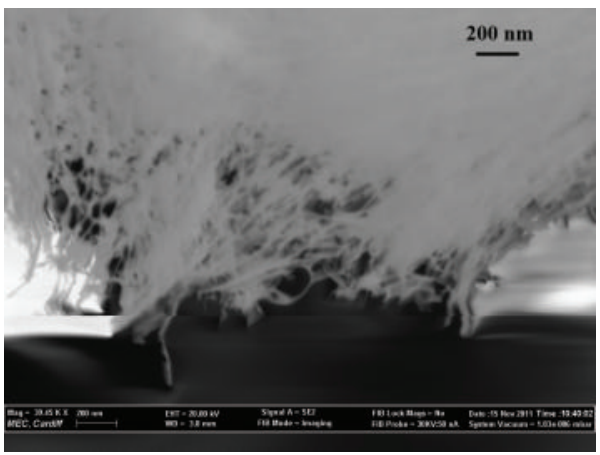

(c)

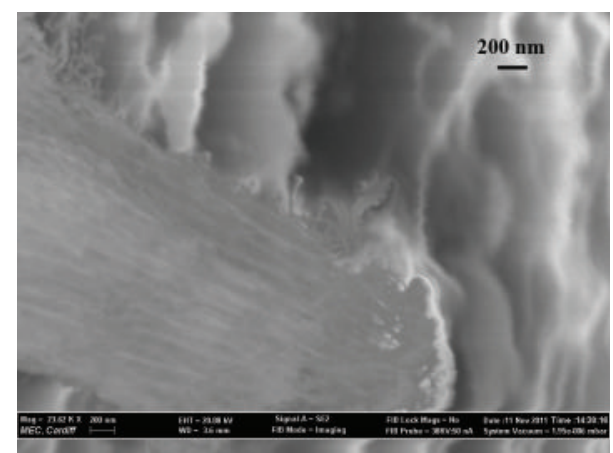

(b)

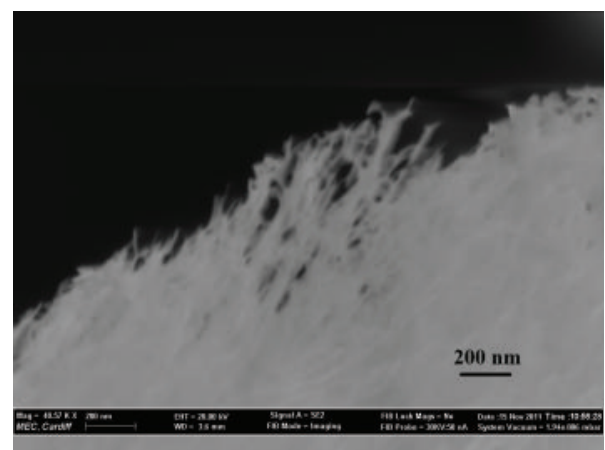

(d)

FIgURE 5: SEM micrographs of the $\mathrm{Al}$ nanowires obtained at ((a), (b)) $17^{\circ} \mathrm{C}$ and ((c), (d)) $19^{\circ} \mathrm{C}$.

capability for dissolving the aluminium ions also increases. A better uniformity of pore distribution could be obtained by utilising a lower anodizing temperature. However, this also comes at the cost of increasing the anodization time. Table 2 also indicates that the average interpore distance and pore density, respectively, increase and decrease with the augmentation of the anodizing temperature. Figure 4 shows a cross-section of the AAO substrate produced at $17^{\circ} \mathrm{C}$ where the high aspect ratio nanochannels are clearly visible. This cross-section was prepared by milling a pocket on the AAO specimen using the FIB system. It should be noted that the surface roughness of the AAO substrate prepared at $25^{\circ} \mathrm{C}$ was observed to be particularly rough. This was a result of instability in current density measured after 8 hours during the second anodization step. Thus, this suggests that such a high temperature is not recommended for the fabrication of AAO specimen.

The thickness of the Al layer deposited on the AAO substrates was $1.4 \mu \mathrm{m}$. Figure 5 shows the obtained SEM micrographs for the nanowires produced at $17^{\circ} \mathrm{C}$ and $19^{\circ} \mathrm{C}$. The AAO substrate prepared at $25^{\circ} \mathrm{C}$ did not lead to the formation of nanowires. This was due to the fact that the surface of this specimen was too rough for ensuring a complete sealing of the AAO pores by the deposited Al. The average diameters of the nanowires were measured to be $55 \mathrm{~nm}$ and $65 \mathrm{~nm}$ for the AAO substrate produced at $17^{\circ} \mathrm{C}$ and $19^{\circ} \mathrm{C}$, respectively. The high aspect ratio of the produced nanowires, which can be seen in Figure 5, is most likely responsible for their agglomeration in a tree-shape structure.

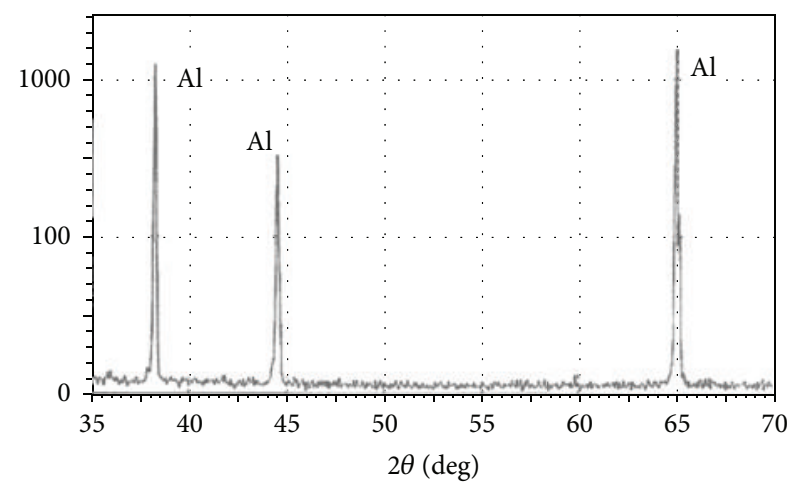

FIGURE 6: XRD spectrum for the $\mathrm{Al}$ nanowires produced with the AAO specimen prepared at $19^{\circ} \mathrm{C}$.

Finally, the XRD spectrum for the Al nanowires synthesis with the AAO substrate produced at $19^{\circ} \mathrm{C}$ is given in Figure 6 . This figure shows the presence of $\mathrm{Al}$ peaks at $(2 \theta)$ values of $38.29^{\circ}, 44.54^{\circ}$, and $64.95^{\circ}$, which are in good agreement with standard XRD tables.

\section{Conclusions}

Compared to other types of metals, studies focussing on the fabrication of nanowires in aluminium are scarce despite their potential applications in high-density and high-resolution microelectronic devices and energy storage systems. The 
research reported here demonstrated that it is possible to use a simple technique that relies on the pressure differential between the inside of the nanochannels of an AAO substrate and the ambient atmosphere to inject molten $\mathrm{Al}$ into the AAO pores. This technique had been investigated previously on one occasion for the formation of $\mathrm{Al}$ nanotubes and referred to as "two-step evaporation method." However, in the case of the study reported here, the technique is more accurately described by the term "differential pressure injection method." In particular, the authors do not believe that evaporation plays a role in filling the AAO pores during the injection process given that the temperature used for this step is just above the melting point of the injected metal. In order to use the technique successfully, this study suggests that it important to ensure a complete sealing of the AAO nanopores through the evaporation of $\mathrm{Al}$ prior to the injection step. However, attention must be paid to ensure that a high level of surface finish is achieved first on the surface of the AAO samples. Thus, future work should focus on this particular aspect as well as on the systematic study of the influence of the applied injection parameters, such as the thickness of the melt and the heating time and temperature, on the characteristics of the synthetized nanowires.

\section{Acknowledgment}

The authors are greatly indebted to the Iraqi Ministry of Higher Education and Scientific Research for supporting this study.

\section{References}

[1] J. Benson, S. Boukhalfa, A. Magasinski, A. Kvit, and G. Yushin, "Chemical vapor deposition of aluminum nanowires on metal substrates for electrical energy storage applications," ACS Nano, vol. 6, no. 1, pp. 118-125, 2012.

[2] S. Michotte, S. Mátéfi-Tempfli, and L. Piraux, "Currentvoltage characteristics of $\mathrm{Pb}$ and $\mathrm{Sn}$ granular superconducting nanowires," Applied Physics Letters, vol. 82, no. 23, Article ID 4119, 3 pages, 2003.

[3] G. S. Cheng, L. D. Zhang, S. H. Chen et al., "Ordered nanostructure of single-crystalline GaN nanowires in a honeycomb structure of anodic alumina," Journal of Materials Research, vol. 15, no. 2, pp. 347-350, 2000.

[4] Y. Bisrat, Z. P. Luo, D. Davis, and D. Lagoudas, "Highly ordered uniform single-crystal Bi nanowires: fabrication and characterization," Nanotechnology, vol. 18, no. 39, Article ID 395601, 2007.

[5] C. Chen, Y. Bisrat, Z. P. Luo, R. E. Schaak, C.-G. Chao, and D. C. Lagoudas, "Fabrication of single-crystal tin nanowires by hydraulic pressure injection," Nanotechnology, vol. 17, no. 2, pp. 367-374, 2006.

[6] C. A. Huber, T. E. Huber, M. Sadoqi, J. A. Lubin, S. Manalis, and C. B. Prater, "Nanowire array composites," Science, vol. 263, no. 5148, pp. 800-802, 1994.

[7] C. J. Smithells and E. A. Brandes, Metals Reference Book, Butterworth-Heinemann, New York, NY, USA, 5fth edition, 1976.

[8] Y. Lin, S. B. Cronin, O. Rabin, J. Y. Ying, and M. S. Dresselhaus, "Transport properties of Bil-x-Sbx alloy nanowires synthesized by pressure injection," Applied Physics Letters, vol. 79, no. 5, pp. 677-679, 2001.

[9] Y. M. Lin, X. Sun, S. B. Cronin, Z. Zhang, J. Y. Ying, and M. S. Dresselhaus, "Fabrication, transport properties of Te-doped Bi nanowire arrays," in Proceedings of the Materials Research Society Fall Meeting, vol. 582, no. 1-6, pp. H10-H13, Boston, Mass, USA, December 1999.

[10] Z. Zhang, J. Y. Ying, and M. S. Dresselhaus, "Bismuth quantumwire arrays fabricated by a vacuum melting and pressure injection process," Journal of Materials Research, vol. 13, no. 7, pp. 1745-1748, 1998.

[11] C. G. Kuo and C. G. Chao, "A novel method of centrifugal processing for the synthesis of lead-bismuth eutectic alloy nanospheres and nanowires," The International Journal of Advanced Manufacturing Technology, vol. 32, no. 5-6, pp. 468472, 2007.

[12] D. D. Sung, M. S. Choo, J. S. Noh, W. B. Chin, and W. S. Yang, "A new fabrication method of aluminum nanotube using anodic porous alumina film as a template," Bulletin of the Korean Chemical Society, vol. 27, no. 8, pp. 1159-1163, 2006.

[13] G. D. Sulka and W. J. Stepniowski, "Structural features of selforganized nanopore arrays formed by anodization of aluminum in oxalic acid at relatively high temperatures," Electrochimica Acta, vol. 54, no. 14, pp. 3683-3691, 2009. 

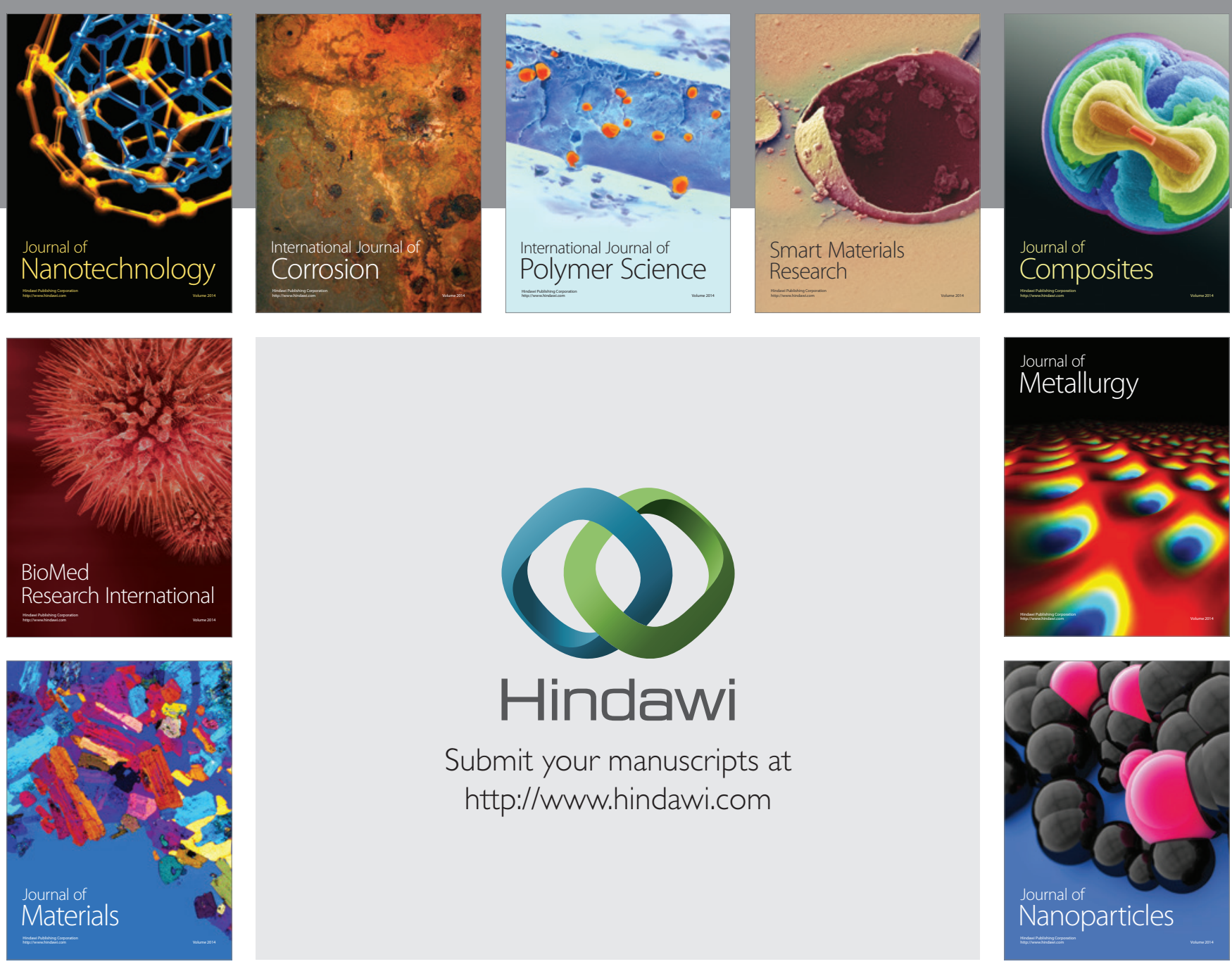

Submit your manuscripts at http://www.hindawi.com
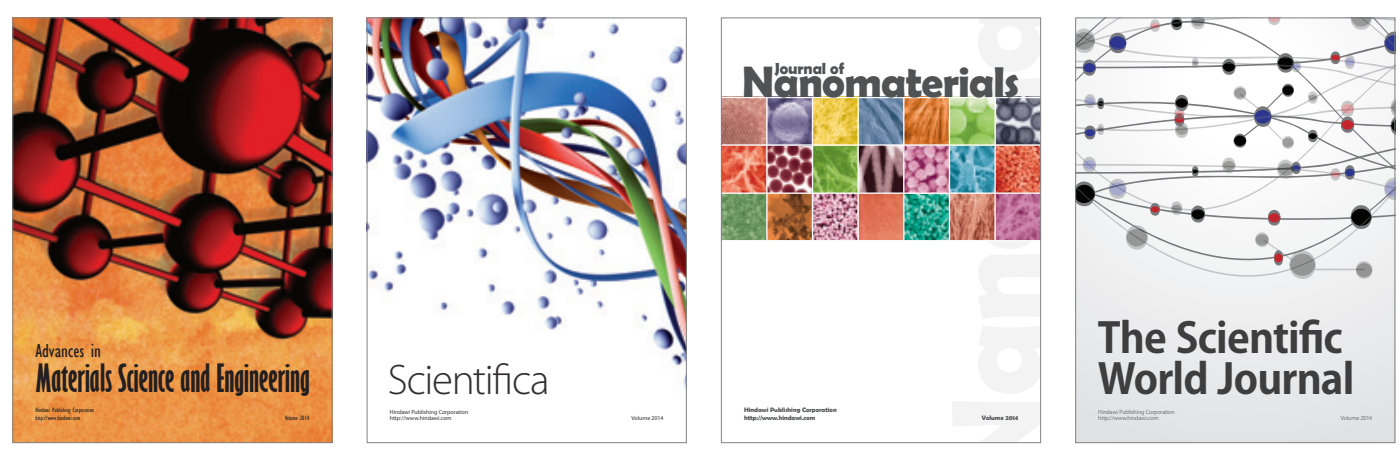

\section{The Scientific World Journal}
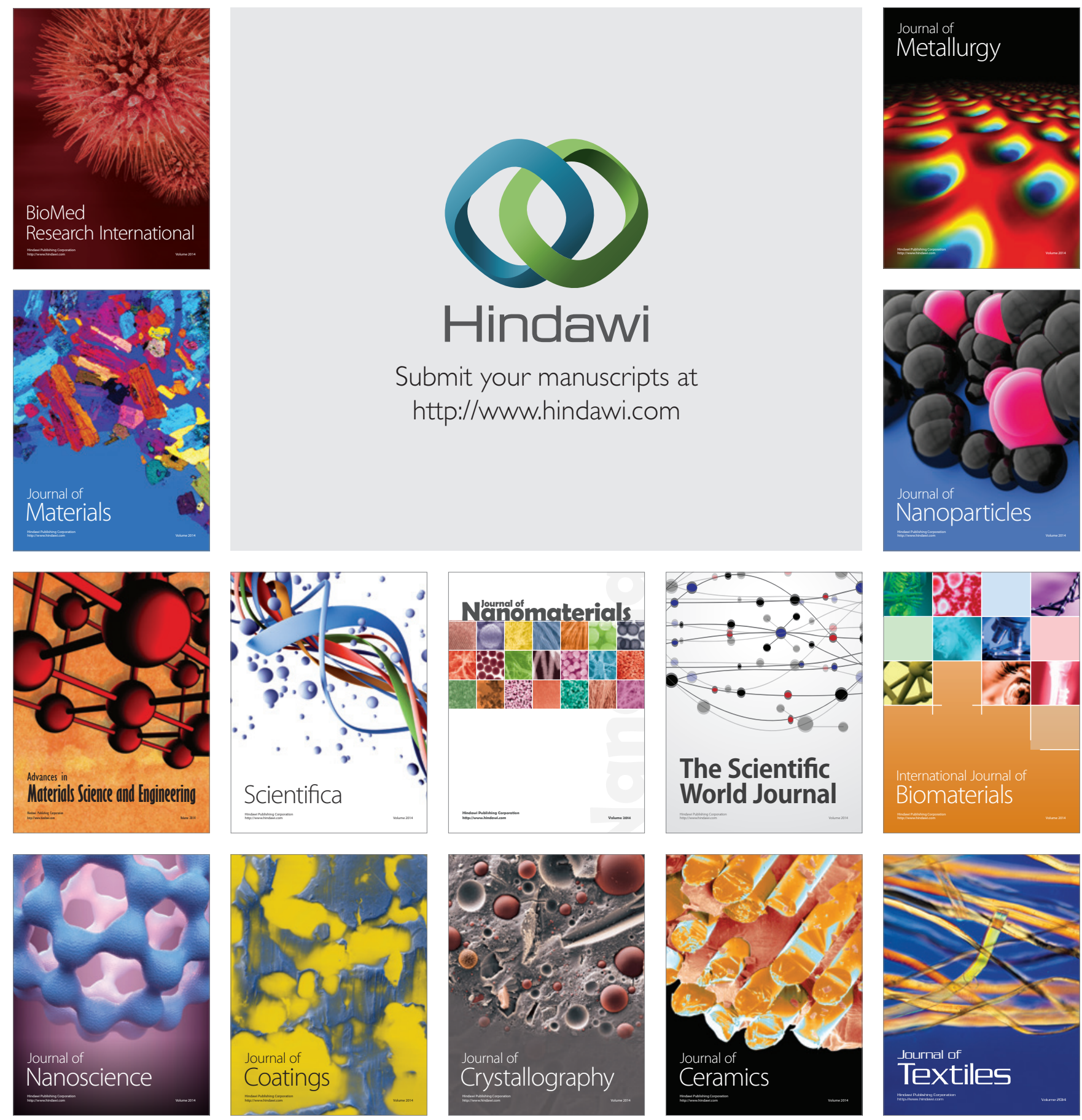